American Journal of Pharmaceutical Education 2017; 81 (5) Article 95.

\title{
REVIEW
}

\section{A Narrative Review of Medication Adherence Educational Interventions for Health Professions Students}

\author{
Matthew J. Witry, PharmD, PhD, ${ }^{a}$ Michelle LaFever, PharmD, ${ }^{\mathrm{b}}$ Xiaomei Gu, $\mathrm{MS}^{\mathrm{a}}$ \\ ${ }^{a}$ University of Iowa College of Pharmacy, Iowa City, Iowa \\ ${ }^{\mathrm{b}}$ Banner University Medical Center, Tucson, Arizona
}

Submitted February 2, 2016; accepted May 18, 2016; published June 2017.

Objective. To review published educational interventions focusing on medication non-adherence.

Methods. A literature search was performed of educational articles on the topic of medication adherence. Data on interventions and learning assessments were abstracted for relevant studies meeting search criteria.

Results. Twenty studies met inclusion criteria. Sixteen included pill-taking experiences with regimens of candies or placebos and varied in their inclusion of novel elements to highlight issues such as stigma, regimen complexity, and adherence measurement. Three studies involved interacting with the public. Qualitative and quantitative methods were used to assess a variety of learning outcomes.

Conclusion. Pill-taking experiences can help future providers appreciate the complex logistics of medication-taking, but are less capable of addressing the psychosocial aspects of adherence. A promising area for learning is to interact with actual medication users to understand their experiences and perspectives.

Keywords: medication adherence, health professional education, simulation, empathy

\section{INTRODUCTION}

Medication non-adherence contributes to significant avoidable mortality, morbidity, and cost worldwide. ${ }^{1}$ Ample research has documented the complex circumstances that contribute to non-adherence and multifaceted interventions have been designed and tested, yet widespread improvements remain elusive. ${ }^{2-8}$

US medical and pharmacy schools are expected to train students in communication and social-behavioral elements of care, including medication adherence, but accreditation standards provide little guidance. ${ }^{9,10}$ Weiden, in a commentary about a curriculum for training resident psychiatric physicians, raised five core competencies related to medication non-adherence. These include defining adherence and its relationship to medication efficacy, assessing adherence, the importance of the therapeutic alliance in promoting adherence, and using theory-based interventions for improving adherence. ${ }^{11}$ The article was not specific in how residents should acquire these perspectives and skills or how programs could assess these competencies.

Corresponding Author: Matthew J. Witry, University of Iowa College of Pharmacy, 115 S. Grand Ave., Iowa City, IA 52242.

Tel: 319-335-8763. E-mail: matthew-witry@uiowa.edu Note: At the time of the study, Michelle LaFever was a doctor of pharmacy candidate, University of Iowa College of Pharmacy.
Pharmacy educators also have called for greater focus on medication non-adherence throughout the curriculum. ${ }^{12,13}$ A survey of pharmacy school faculty showed the majority of responding colleges $(90 \%)$ provided some form of non-adherence education as a required component of the PharmD curriculum, delivered through lecture, experiences, or cases. For many of the adherence topics, however, students perceived they were only "somewhat" or "moderately" covered. ${ }^{14}$

The rationale for this review is that a comprehensive assessment of medication adherence interventions and their learning assessments will allow educators across disciplines to implement evidence-based activities that enhance student learning and spur educational innovation in areas that have received less attention. There is a need to develop novel educational interventions specific to medication non-adherence for health professions students as this topic appears infrequently addressed given the importance of the problem to public health and patient outcomes. ${ }^{12}$ After all, in the words of former U.S. Surgeon General C. Everett Coop, “drugs don't work in patients that don't take them."

\section{METHODS}

\section{Data and Search Terms}

A comprehensive search of the English-language literature was performed using the following databases: 


\section{American Journal of Pharmaceutical Education 2017; 81 (5) Article 95.}

MEDLINE/PubMed, ERIC, Embase. Also, the American Journal of Pharmaceutical Education (AJPE) website was searched. Combined terms were searched based on three components, a medication adherence term (adherence, compliance, concordance) with a student term (pharmacy, medical, dental, nursing) and an educational term (educat*, teach*, course, lecture, activity, simulat*, lab*, instruct*, student, learn, experien*). The search for English language articles was performed in February 2015, August 2015, and April 2016 without date limits. Exact syntax available upon request. Articles were analysed and reviewed for relevance. Reference lists from included articles also were reviewed.

\section{Inclusion and Exclusion Criteria}

Two authors screened titles and abstracts to identify relevant articles. Studies were required to address medication adherence, compliance, or concordance as well as some educational element as the main inclusion criteria. Educational interventions broadly dealing with communication, empathy training, motivational interviewing, or shared decision-making, without specific mention of adherence or compliance as a learning focus were excluded. The justification for this exclusion criteria was to focus the review and treat adherence as a specific topic to be addressed, not just a hypothetical outcome of the aforementioned communication approaches. Full texts were assessed for final inclusion by both authors, discussing and resolving any discrepancies. The following descriptive elements were abstracted to provide an overview of the studies: learning objectives, qualitative and quantitative methods for learning assessment, novel activity elements.

\section{RESULTS}

The Embase and Medline searches identified 747 articles, 424 unique to Embase, 115 unique to Medline, and 208 identified in both. Of these, 20 articles involved health professions and an educational intervention targeted at the provider on the topic of medication adherence or compliance, therefore meeting the criteria for inclusion. Eight studies were conducted since 2010, seven from 2000 to 2010 , three in the 1990s, and two prior to 1990. Studies switched terminology in the early 2000 s from compliance to adherence. Five studies involved only medical/osteopathic students, 10 only involved pharmacy students, and four reports described interdisciplinary activities.

Most studies (16/20) involved a placebo pill-taking experience (Table 1), four included activities in conjunction with pill-taking experiences, and four addressed adherence without a pill-taking experience. Surveys were the primary method for evaluating the learning outcomes of these educational activities.

\section{Pill-taking experiences}

Sixteen studies documented a simulated pill-taking experience, generally lasting from 1 to 4 weeks. The objectives were generally to increase the future provider's empathy for patients taking medications and the challenges associated with adhering to a regimen. The placebo-taking experiences varied in intensity and methods. There was a wide range of types of placebo mediation taken, varying from M\&Ms and Tic-Tacs to gelatine capsules and placebo inhalers, with varying instructions (Table 1). Adherence measurement and reporting commonly were used to reinforce learning objectives during class discussions.

\section{Experience-based activities}

Four reports described the combination of a pill-taking exercise with an additional activity. Darbishire and colleagues built upon the pill-taking simulation by having students apply their adherence training to help actual patients they identified as non-adherent from a local community pharmacy. ${ }^{15}$ Students provided patients with a medication-dispensing device and counseled on its use. In Adamcik and colleagues' article, third-year pharmacy students counseled first-year pharmacy students on their placebo regimen to support adherence. ${ }^{16}$ In Volion and colleagues' article, students were randomized to receive either a monograph or a monograph plus counseling about dietary restrictions related to the placebo. ${ }^{17}$ Chen and colleagues designed "patient empathy modelling" assignments for pharmacy students to complete on their APPEs that had students "become the patient" for a 10-day experience of considering difficulties such as homelessness and illiteracy. ${ }^{18}$

Four articles addressed adherence without a pilltaking experience, Grice and colleagues paired students with residents of an independent-living facility for seniors as part of an introductory practice experience for third-year pharmacy students. ${ }^{19}$ Students met with their residents to discuss their medications and then wrote about their resident's barriers to adherence and provided education to overcome the barriers. Kripalani described a workshop that uses a combination of didactic learning and role play to enhance resident physician knowledge and skills relating to adherence counseling. ${ }^{20}$ Miller described an objective structured clinical examination (OSCE) focusing on cross-cultural skills involving a simulated patient with medication non-adherence to help resident physicians understand the importance of eliciting patient perspectives 


\section{American Journal of Pharmaceutical Education 2017; 81 (5) Article 95.}

Table 1. Placebo Exercise Modifications With Intended Learning Objective

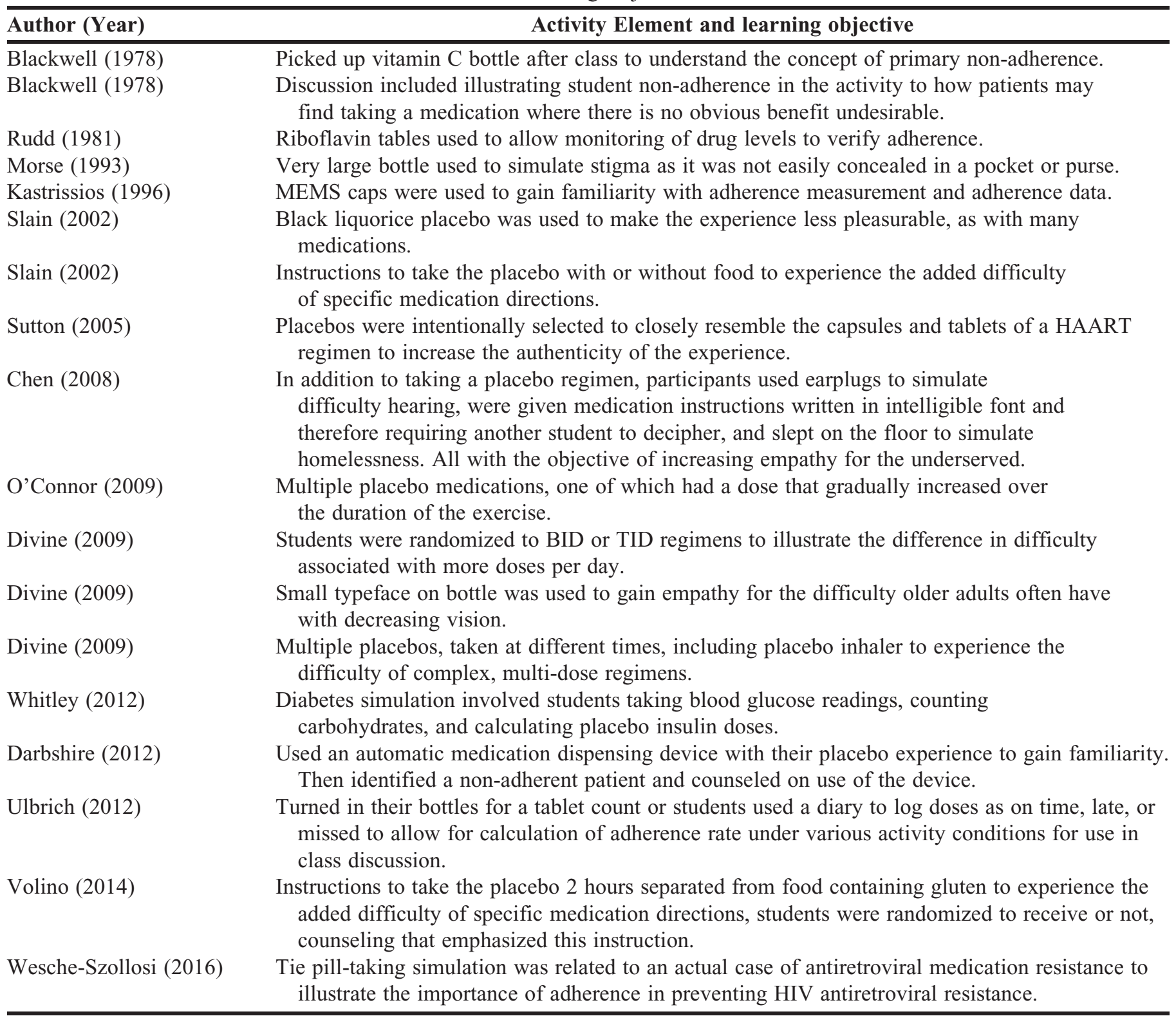

and exploring non-adherence. ${ }^{21}$ Lastly, Sobota briefly described a service learning activity where pharmacy students team with nursing students to deliver presentations at community centers that involve adherence as a topic. $^{22}$

\section{Interdisciplinary experiences}

Singla and colleagues documented an interdisciplinary experience that students from different disciplines interacted through different roles. ${ }^{23}$ Doctor of Osteopathy students were given a placebo HAART regimen to take for four weeks and were randomized to different levels of counseling by student pharmacists to demonstrate the potential impact of pharmacist counseling on adherence. ${ }^{23}$
Three studies involved multiple providers engaging in the same activity and role. ${ }^{22,24,25}$

\section{Quantitative assessments}

A mix of newly developed and previously validated scales were used to assess changes in empathy, understanding of medication adherence, and ability to counsel patients on adherence, teamwork, and overall activity satisfaction. In Singla and colleagues, osteopathic medical students and pharmacy students reported increased empathy related to adherence, a better understanding of medication adherence, and a greater ability to work as a health care team. ${ }^{23} \mathrm{O}$ 'Connor incorporated select questions from a previously validated instrument, the Leeds Concordance 


\section{American Journal of Pharmaceutical Education 2017; 81 (5) Article 95.}

Attitude Scale, ${ }^{24}$ and Kripalani used a combination of new and previously developed measures of physicianpatient communication. ${ }^{20,26}$ Ulbricht used a pre-post design with a quantitative measure comparing anticipated and actual difficulty with adhering to the placebo regimen. ${ }^{27}$ Two studies assessed learning as operationalized by changes in knowledge and attitudes based on a preand post-activity survey, combined with a comparison group; however, neither demonstrated a statistically significant difference. ${ }^{24,28}$ Quantitative analyses also were used to test differences in adherence rates for students randomized to twice daily or thrice daily regimens to illustrate the increased difficulty of adhering to additional doses per day. ${ }^{29}$

\section{Qualitative assessments}

The primary use for formal qualitative methods was to perform content analysis or thematic analysis on the open-ended responses contained in surveys. For example, content analysis was used by Kastrissios and colleagues to code the adherence barriers and strategies for remembering doses experienced by students and reported on their post-activity surveys. Darbishire and colleagues used a unique approach of comparing student recall of adherence reasons before and after the experience. ${ }^{15}$ Sutton and colleagues interviewed participants to identify what was learned and suggested changes. ${ }^{28}$ Students agreed it was a useful exercise and most experienced the difficulty of following a regimen and a perceived gain in empathy. In Divine and colleagues' article and the article by Whitley, activity reflections were coded and analysed using thematic analysis. ${ }^{30,31}$ Students commonly mentioned barriers such as time constraints and identified increased empathy as an activity outcome, represented by phrases such as "being in another's shoes." In Grice and colleagues' article where students met with community-dwelling elders, reflections from student diaries commonly reported that visiting a patient's home and discussing their regimens was eye-opening for understanding issues related to medication taking. ${ }^{19}$ In Miller and colleagues' article, participant interviewees spoke to the importance of eliciting the patients' perspectives, asking how they take their medications (including complementary medicines) and exploring the reasons for non-adherence in the context of cultural awareness. ${ }^{21}$

\section{Debriefing/Discussion topics}

Facilitators often led debriefing discussions following the activities, which allowed participants to share their experiences with the class or group. Kastrissios and colleagues prompted students with questions about how they handled missed doses and what strategies they used to remember to take their medications. ${ }^{16}$ In studies with tablet counts, some instructors analyzed the data and reported to the class descriptive statistics of adherence rates to demonstrate the difference between a twice and thrice daily regimens. ${ }^{29,32}$

\section{Instructor reflections of student learning}

Instructors commonly attested to overall activity success and achievement of learning outcomes in article discussion sections. Authors also proposed hypotheses about why some students did not engage fully in the activity. Kastrissos and colleagues suggested student non-adherence could be due to a lack of benefit from the regimen and used this as a teaching point as many prescribed medications have no observable benefit to patients. ${ }^{29}$ Activity leaders in the Divine and colleagues' article reported students engaged in peer learning by sharing their strategies for remembering doses. ${ }^{30}$

\section{DISCUSSION}

Most efforts to provide students with learning opportunities related to medication adherence involved simulated pill-taking experience over one to four weeks. Based on the stated learning objectives and assessments, pill-taking experiences appear to give health professions students a worthwhile exposure to logistics of medication-taking challenges of their future patients. Faculty looking to craft such a simulation have numerous modifications from which to choose (Table 1). Simulations, however, are brief and are inherently limited as they cannot provide an equivalent experience to the real-life burdens of medication taking.

Multiple enhancements to the pill-taking exercise were used to address important topics related to adherence. For example, stigma was highlighted with the use of a large bottle. While inconvenient, this likely did not affect students' identity to the extent of an individual living with a stigmatized illness. Making the placebo less palatable appears to be a positive step; however, knowing the placebo is inert likely failed to bring about genuine concern about side effects, which are common among actual medication users. ${ }^{33}$ Instructors drawing attention to these design elements of the activity in debriefing sessions appear to be useful for student learning as evident by student reflections, which also appear to be important opportunities for students to demonstrate and reinforce their learning. Placebo simulations, if used as the only means for students to gain experience and perspective with medication non-adherence, may give students the false impression that non-adherence is mostly due to patients being 


\section{American Journal of Pharmaceutical Education 2017; 81 (5) Article 95.}

careless, forgetful, or defiant and therefore to blame for their non-adherence. It is imperative that students learn how the health care system, different therapies and conditions, and social and economic factors, all contribute to non-adherence. ${ }^{1}$

Medication non-adherence is a complex phenomenon, and issues such as belief-based reasons for nonadherence, prescription cost issues, and the meaning of medications in chronic illnesses have not received as much attention as logistical reasons for non-adherence and issues of busyness and forgetfulness. During debriefing sessions, some instructors appeared to highlight the similarities between the low necessity beliefs of the students in regard to the placebos and the low necessity beliefs of many patients taking medications for chronic illness where there may be little observable effect. The studies by Grice and Darbishire, through exposure to actual patients, provided unique experiences for students as they get the opportunity to listen to the illness and medication beliefs of actual persons with chronic illness which can make space for empathy. ${ }^{15,19}$ Additional activities and assessments in the area of medication beliefs and experiences are needed.

Several resources and initiatives not in the peerreviewed literature also were identified, which include the AACP/NCPA Medication Adherence Educators Toolkit, the Script Your Future campaign, and potentially others. The literature search also identified conference abstracts on adherence education topics, including claims-based adherence measurement and activities combining adherence and motivational interviewing. Medication adherence educators should be encouraged to perform learning assessments and describe their activities for publication so that other educators can learn from their experiences. Similarly, given the interest in teambased care and concepts such as medical homes, it may be wise to put more resources into interdisciplinary education endeavors that include the entire health care team.

This review also provides an opportunity to evaluate the rigor of the scholarship of teaching and learning in this area. Quantitative assessments using previously validated measures and qualitative assessments using thematic or other formal analyses should be prioritized over general instructor impressions, which were particularly present in the earlier studies. It is encouraging to see the transition of over 40 years of research on adherence education to a more systematic assessment of learning. More work, however, can be done including the use of educational models and theories and applying more rigorous quantitative and qualitative learning assessments. Similarly, while overall satisfaction questions such as "this was a valuable activity" are common, they may be subject to social desirability bias and may simply serve to confirm what the instructor probably already intuited. More specific items, administered before and after the activity are needed to assess learning outcomes. If attitudes and concepts such as empathy development are the goal, then items specific to these concepts need to be assessed. For example, there are published empathy measures and these can provide more robust evidence that an activity achieves the learning objectives. Ultimately, a more comprehensive sequence of activities may be needed to move these self-reported numbers as the studies in this review generally did not show statistically significant improvements in scaled responses when comparisons were made to students in a control group.

\section{CONCLUSION}

Pill-taking experiences, which help students appreciate the barriers to medication adherence, were the predominant mode of facilitating student learning of non-adherence issues in the health professions' educational literature. Faculty implementing this as an active learning strategy have numerous activity elements from which to choose. Given the numerous published examples, however, the academy should move away from more repeat studies to more novel means of medication adherence education such as those that involve interactions with actual patients which can offer opportunities to appreciate psychosocial issues of adherence. Overall, the rigor of the learning assessments in this area is increasing, although with room for improvement.

\section{REFERENCES}

1. Sabaté E. Adherence to Long-term Therapies: Evidence for Action. Geneva, Switzerland: World Health Organization; 2003.

2. Sokol MC, McGuigan KA, Verbrugge RR, Epstein RS. Impact of medication adherence on hospitalization risk and health care cost. Med Care. 2005;43(6):521-530.

3. Cutler DM, Everett W. Thinking outside the pillbox - medication adherence as a priority for health care reform. $N$ Engl J Med. 2010;362(17):1553-1555.

4. Osterberg L, Blaschke T. Adherence to medication. N Engl J Med. 2005;353(5):487-497.

5. Donovan JL, Blake DR. Patient non-compliance: deviance or reasoned decision-making? Soc Sci Med. 1992;34(5):507-513.

6. Horne R, Weinman J, Hankins M. The beliefs about medicines questionnaire: the development and evaluation of a new method for assessing the cognitive representation of medication. Psychology and health. 1999;14(1):1-24.

7. DiMatteo MR, Haskard-Zolnierek KB, Martin LR. Improving patient adherence: a three-factor model to guide practice. Health Psychol Rev. 2012;6(1):74-91.

8. DiMatteo MR. Variations in patients' adherence to medical recommendations: a quantitative review of 50 years of research. Med Care. 2004;42(3):200-209.

9. Liaison Committee on Medical Education. Functions and structure of a medical school: standards for accreditation of medical education programs leading to the MD degree. 2014. 


\section{American Journal of Pharmaceutical Education 2017; 81 (5) Article 95.}

10. Accreditation Council for Pharmacy Education. Accreditation standards and guidelines for the professional program in pharmacy leading to the doctor of pharmacy degree. 2006.

11. Weiden PJ, Rao N. Teaching medication compliance to psychiatric residents: placing an orphan topic into a training curriculum. Acad Psych. 2005;29(2):203-210.

12. Marie-Schneider P, Aslani P. Adherence policy, education and practice - an international perspective. Pharm Pract. 2010;8(4):209212.

13. Rickles NM, Brown TA, McGivney MS, Snyder ME, White KA. Adherence: a review of education, research, practice, and policy in the United States. Pharm Pract. (Granada). 2010;8(1):1-17. 14. Rickles NM, MacLean LG, Hess K, et al. Teaching medication adherence in US colleges and schools of pharmacy. Am J Pharm Educ. 2012;76(5):Article 79.

15. Darbishire PL, Plake KS, Kiersma ME, White JK. An introductory pharmacy practice experience on improving medication adherence. Am J Pharm Educ. 2012;76(3):Article 42.

16. Adamcik B, Airmet D. Multi-cohort learning: teaching pharmacy students about compliance, counseling and mentoring. Am J Pharm Educ. 1998;62(3):342-346.

17. Volino LR, Das RP, Mansukhani RP, Cosler LE. Evaluating the potential impact of pharmacist counseling on medication adherence using a simulation activity. Am J Pharm Educ. 2014;78(9):Article 169.

18. Chen JT, LaLopa J, Dang DK. Impact of patient empathy modeling on pharmacy students caring for the underserved. Am J Pharm Educ. 2008;72(2):Article 40.

19. Grice GR, Tiemeier A, Hurd P, et al. Student use of health literacy tools to improve patient understanding and medication adherence. Consultant Pharm. 2014;29(4):240-253.

20. Kripalani S, Osborn CY, Vaccarino V, Jacobson TA.

Development and evaluation of a medication counseling workshop for physicians: can we improve on 'take two pills and call me in the morning'? Med Educ Online. 2011;16.

21. Miller E, Green AR. Student reflections on learning crosscultural skills through a 'cultural competence' OSCE. Med Teach. 2007;29(4):e76-e84.
22. Sobota KF, Barnes J, Fitzpatrick A, Sobota MJ. Pharmacy student learning through community service. Consult Pharm. 2015;30(7):413-416.

23. Singla DL, MacKinnon GE, 3rd, MacKinnon KJ, Younis W, Field B. Interdisciplinary approach to teaching medication adherence to pharmacy and osteopathic medical students. $J$ Am Osteopath Assoc. 2004;104(3):127-132.

24. O'Connor DM, Savageau JA, Centerbar DB, Wamback KN, Ingle JS, Lomerson NJ. Lesson in a pill box: teaching about the challenges of medication adherence. Fam Med. 2009;41(2):99-104. 25. Morse EV, Simon PM, Balson PM. Using experiential training to enhance health professionals' awareness of patient compliance issues. Acad Med.1993;68(9):693-697.

26. Jenkins L, Britten N, Stevenson F, Barber N, Bradley C. Developing and using quantitative instruments for measuring doctorpatient communication about drugs. Patient Educ Couns. 2003;50 (3):273-278

27. Ulbrich T, Hamer D, Lehotsky K. Second-year pharmacy students' perceptions of adhering to a complex simulated medication regimen. Am J Pharm Educ. 2012;76(1):Article 11.

28. Sutton EL, Transue ER, Comes S, Paauw DS. Placebo HAART regimen as a method for teaching medication adherence issues to students. J Gen Intern Med. 2005;20(6):541-545.

29. Kastrissios H, Flowers NT, Blaschke TF. Introducing medical students to medication noncompliance. Clin Pharm Ther. 1996;59 (5):577-582.

30. Divine HS, Cain J. Assessing the effect of a polypharmacy medication adherence simulation project in a geriatrics course in a college of pharmacy. J Am Geriatr Soc. 2009;57(8):1487-1491. 31. Whitley HP. Active-learning diabetes simulation in an advanced pharmacy practice experience to develop patient empathy. Am J Pharm Educ. 2012;76(10): Article 203.

32. Slain D, Casdorph D, McIntire T. Assessment of an antiretroviral adherence sensitivity training exercise in the doctor of pharmacy curriculum. Am J Pharm Educ. 2002;66(3):277-279.

33. McHorney CA, Gadkari AS. Individual patients hold different beliefs to prescription medications to which they persist vs nonpersist and persist vs nonfulfill. Patient Prefer Adherence. 2010;4:187-195. 